\title{
Spectroscopy of $\mathrm{Na}^{+} \cdot \mathbf{R g}$ and transport coefficients of $\mathrm{Na}^{+}$ in $\mathbf{R g}(\mathbf{R g}=\mathrm{He}-\mathrm{Rn})$
}

\author{
Larry A. Viehland ${ }^{\text {a) }}$ \\ Division of Science, Chatham College, Pittsburgh, Pennsylvania 15232 \\ Jérôme Lozeille \\ Department of Chemistry, University of Sussex, Falmer, Brighton, BN1 9QJ, United Kingdom
}

Pavel Soldán

Department of Chemistry, University of Durham, South Road, Durham, DH1 3LE, United Kingdom

Edmond P. F. Lee ${ }^{\text {b) }}$

Department of Chemistry, University of Southampton, Highfield, Southampton, SO17 1BJ, United Kingdom, and Department of Applied Biology and Chemical Technology, Hong Kong Polytechnic University, Hung Hom, Hong Kong

Timothy G. Wright ${ }^{\mathrm{c})}$

Department of Chemistry, University of Sussex, Falmer, Brighton, BN1 9QJ, United Kingdom

(Received 23 April 2003; accepted 21 May 2003)

High-level $a b$ initio calculations are used to obtain accurate potential energy curves for $\mathrm{Na}^{+} \cdot \mathrm{Kr}$, $\mathrm{Na}^{+} \cdot \mathrm{Xe}$, and $\mathrm{Na}^{+} \cdot \mathrm{Rn}$. These data are used to calculate spectroscopic parameters for these three species, and the data for the whole $\mathrm{Na}^{+} \cdot \mathrm{Rg}$ series $(\mathrm{Rg}=\mathrm{He}-\mathrm{Rn})$ are compared. Potentials for the whole series are then used to calculate both mobilities and diffusion coefficients for $\mathrm{Na}^{+}$moving through a bath of each of the six rare gases, under conditions that match previous experimental determinations. Different available potentials and experimental data are then statistically compared. It is concluded that the present potentials are very accurate. The potential and other data for $\mathrm{Na}^{+}$ - Rn appear to be the first such reported. (c) 2003 American Institute of Physics.

[DOI: $10.1063 / 1.1591171]$

\section{INTRODUCTION}

We have recently been involved in the generation of accurate $a b$ initio potential energy curves for the alkali metal/ rare gas 1:1 complexes and the derivation, from these, of spectroscopic constants and transport coefficients. To date, we have reported the whole set of results for $\mathrm{Li}^{+} \cdot \mathrm{Rg}(\mathrm{Rg}$ $=\mathrm{He}-\mathrm{Rn})^{1,2}$ and the potential energy curves and spectroscopy of $\mathrm{Na}^{+} \cdot \operatorname{Rg}(\mathrm{Rg}=\mathrm{He}-\mathrm{Ar}){ }^{3}$ This work follows on from these results and from previous work by one of us ${ }^{4,5}$ where interaction potentials were derived from transport data. In the present work, we present ab initio potential energy curves and derive spectroscopic quantities for the three heavier species, $\mathrm{Na}^{+} \cdot \mathrm{Kr}, \mathrm{Na}^{+} \cdot \mathrm{Xe}$ and $\mathrm{Na}^{+} \cdot \mathrm{Rn}$, as well as transport coefficients for the whole $\mathrm{Na}^{+} \cdot \mathrm{Rg}$ series. We shall compare our calculated spectroscopic and transport results with previously available values, particularly the spectroscopic work on $\mathrm{M}^{+} \cdot \mathrm{Rg}$ species summarized in a recent review ${ }^{6}$ and the transport data referred to below. Complexes involving an alkali metal cation interacting with a rare gas atom are prototypical closed-shell neutral/closed-shell cation species. They are simple enough that very accurate calculations can be performed, so providing insight into the fundamental interactions that occur in this model microsolvation system. ${ }^{6}$

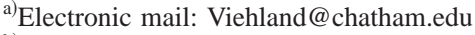

${ }^{b)}$ Electronic mail: e.p.lee@soton.ac.uk

${ }^{c}$ Electronic mail: t.g.wright@sussex.ac.uk
}

A number of previous studies are of relevance here. Kim and Gordon provided early attempts to describe the attractive and repulsive parts of the interaction potential of closedshell/Rg systems. ${ }^{7,8}$ Waldman and Gordon ${ }^{9}$ have reported the results of the most recent (modified) electron gas modeling, although an earlier study by Gianturco had been published. ${ }^{10}$ Powers and Cross ${ }^{11}$ have reported the results of ion beam scattering studies, as have Gislason ${ }^{12}$ and Kita et al..$^{13}$ Viehland ${ }^{4,14}$ derived potential parameters from ion scattering and transport data, and subsequently Koutselos et al. ${ }^{5}$ developed a universal scaling scheme that provided good agreement with experiment for all alkali metal/rare gas systems (excepting species involving $\mathrm{Fr}$ and $\mathrm{Rn}$ ). Nyland et al. ${ }^{15}$ considered the interaction potentials of $\mathrm{Na}^{+} \cdot \mathrm{Kr}$ and $\mathrm{Na}^{+} \cdot$ Xe using a range of fitting and combination rules. Finally, Freitag et al. ${ }^{16}$ reported results for $\mathrm{Na}^{+} \cdot \mathrm{Xe}$ using SCF and CEPA methods.

\section{THEORETICAL DETAILS}

\section{A. Ab initio calculations}

The interatomic curves were computed at the $\operatorname{CCSD}(\mathrm{T})$ level of theory using a derived ${ }^{17}$ basis set equivalent to an aug-cc-pVQZ basis set for $\mathrm{Na}^{+}$. The standard version of these basis sets was used for $\mathrm{He}, \mathrm{Ne}$, and $\mathrm{Ar}$, as reported in Ref. 3. For $\mathrm{Kr}$, the ECP28MWB ${ }^{18}$ effective core potential (ECP) was employed. Here and below, the M generally indicates that the neutral atom is used in the derivation of the 
ECP, and WB implies the use of the quasirelativistic approach described by Wood and Boring; ${ }^{19}$ the number indicates the number of electrons which are included in the core. To this was added a $[8 s 7 p 5 d 3 f 2 g]$ valence basis set as detailed in Ref. 2. For Xe, the ECP46MWB ${ }^{18}$ ECP was employed, to which was added a $[6 s 6 p 4 d 3 f 2 g]$ valence basis set detailed in Ref. 2. For Rn, the ECP78MWB ${ }^{20}$ ECP was employed, augmented by a $[10 s 9 p 7 d 4 f 2 g]$ valence basis set: this basis set has been given explicitly in Refs. 21 and 22 .

Energies were determined at a range of intermolecular separations, $R$, covering the short- as well as long-range regions. The ranges of $R$ used were selected based upon the position of the minimum and upon the demands of the transport property calculations. Basis set superposition error (BSSE) was accounted for by employing the full counterpoise correction of Boys and Bernardi ${ }^{23}$ in a point-by-point manner. All energy calculations were performed employing MOLPRO. ${ }^{24}$ The frozen core approximation was used throughout, with the $2 s$ and $2 p$ electrons of $\mathrm{Na}^{+}$treated as valence. We showed in Ref. 17 that the freezing of the core orbitals had a negligible effect on the calculated dissociation energy and equilibrium bond length; indeed, freezing these orbitals had the beneficial effect of reducing the BSSE. The frozen core approximation obviously affects the calculated total energy, but our previous calculations with the $\mathrm{Li}^{+} \cdot \mathrm{Rg}$ systems $^{1,2}$ indicate that it has a negligible effect upon the calculated interaction potential energies.

\section{B. Spectroscopy and interaction parameters}

From the interaction potential energy functions, the equilibrium interatomic separations and the dissociation energies were obtained, and LeRoy's LEVEL program $^{25}$ was used to calculate rovibrational energy levels. The $\omega_{e}$ and $\omega_{e} x_{e}$ parameters were then determined from the calculated energy levels by straightforward means.

\section{Transport coefficients}

Starting from the interaction potentials, transport cross sections were calculated to an accuracy of $0.1 \%$ using the program $^{\text {QVALUES. }}{ }^{26,27}$ These cross sections were then used in the program GRAMCHAR ${ }^{28}$ to determine the ion mobility and the other gaseous ion transport coefficients as functions of $E / N$, the ratio of the electric field strength to the gas number density, at particular gas temperatures. The mobilities are generally precise within $0.1 \%$, which means that the numerical procedures within the programs QVALUES and GRAMCHAR have converged within $0.1 \%$ for the given ionneutral interaction potential. However, at some intermediate $E / N$ values convergence is sometimes only within a few tenths of a percent and a slight wobble is detectable in the computed values for the heavier rare gases. The diffusion coefficients are generally precise within $1 \%$, with the exception of intermediate $E / N$ values where convergence is only within $3 \%$.
TABLE I. Potentials for $\mathrm{Na}^{+} \cdot \mathrm{Rg}$ : the energies are given in $\mathrm{cm}^{-1}$, with respect to the relevant dissociation limit.

\begin{tabular}{rrrr}
\hline \hline & & $\mathrm{V}(\mathrm{R}) / \mathrm{cm}^{-1}$ & \\
\cline { 2 - 4 }$R / \AA$ & \multicolumn{1}{c}{$\mathrm{Na}^{+} \cdot \mathrm{Kr}$} & $\mathrm{Na}^{+} \cdot \mathrm{Xe}$ & \multicolumn{1}{c}{$\mathrm{Na}^{+} \cdot \mathrm{Rn}$} \\
\hline 2.000 & 14978.206 & 28550.083 & 35301.860 \\
2.300 & 2501.035 & 7319.638 & 10152.053 \\
2.400 & 754.059 & 3946.776 & 5966.843 \\
2.500 & -362.443 & 1627.742 & 3011.228 \\
2.600 & -1046.239 & 66.584 & 956.434 \\
2.700 & -1435.992 & -952.903 & -441.124 \\
2.800 & -1628.650 & -1588.206 & -1361.655 \\
2.900 & -1691.798 & -1953.746 & -1938.421 \\
3.000 & -1672.267 & -2132.424 & -2269.793 \\
3.100 & -1602.272 & -2184.060 & -2428.214 \\
3.200 & -1503.724 & -2151.616 & -2466.863 \\
3.300 & -1391.284 & -2065.737 & -2424.602 \\
3.400 & -1274.571 & -1948.091 & -2329.701 \\
3.500 & -1159.681 & -1813.805 & -2202.589 \\
3.800 & -855.020 & -1398.531 & -1753.606 \\
4.100 & -625.769 & -1045.462 & -1334.499 \\
4.400 & -462.352 & -778.059 & -1001.700 \\
4.700 & -347.268 & -583.967 & -753.850 \\
5.000 & -265.620 & -444.633 & -573.593 \\
6.000 & -122.201 & -201.020 & -257.194 \\
8.000 & -37.186 & -60.305 & -76.448 \\
10.000 & -15.019 & -24.238 & -30.623 \\
13.000 & -5.232 & -8.403 & -10.602 \\
15.000 & -2.958 & -4.737 & -5.973 \\
17.000 & -1.805 & -2.879 & -3.627 \\
20.000 & -0.960 & -1.519 & -1.898 \\
22.000 & -0.667 & -1.049 & -1.318 \\
25.000 & -0.416 & -0.645 & -0.807 \\
\hline \hline
\end{tabular}

\section{RESULTS AND DISCUSSION}

Our ion-neutral interaction potential energies are given in Table I. For a closed-shell atom interacting with a singly charged ion at long range

$$
U(R)=-\frac{D_{4}}{R^{4}}-\frac{D_{6}}{R^{6}}+\cdots=E_{\text {ind }}(R)+E_{\text {disp }}(R),
$$

where

$$
\begin{aligned}
& E_{\text {ind }}(R)=-\frac{1}{2}\left(\frac{\alpha_{1}}{R^{4}}+\frac{\alpha_{2}}{R^{6}}+\cdots\right), \\
& \text { and } E_{\text {disp }}(R)=-\frac{C_{6}}{R^{6}}-\frac{C_{8}}{R^{8}}+\cdots,
\end{aligned}
$$

where $E_{\text {ind }}$ is the induction energy, $E_{\text {disp }}$ is the dispersion energy, $\alpha_{1}$ is the static dipolar polarizability (or simply static polarizability), and $\alpha_{2}$ is the static quadrupolar polarizability of the rare gas atom. Ignoring the higher order terms, Ahlrichs et al. ${ }^{29}$ (among others) have noted that $D_{4}$ and $D_{6}$ are related to the other parameters by

$$
\begin{aligned}
& D_{4}=\alpha_{1} / 2, \\
& D_{6}=\alpha_{2} / 2+C_{6}\left(\mathrm{Na}^{+} \cdot \mathrm{Rg}\right) .
\end{aligned}
$$

As a consequence of Eqs. (4) and (5), least-squares fitting of the calculated potentials at large $R$ to Eq. (1) should yield values for the parameters $D_{4}$ and $D_{6}$. Note that it is also possible to incorporate "universal damping functions" 
TABLE II. Calculated spectroscopic parameters for ${ }^{23} \mathrm{Na}^{+} \cdot \mathrm{Rg}$. Bold values are those calculated in the present work.

\begin{tabular}{lllll}
\hline \hline Species & \multicolumn{1}{c}{$R_{e} / \AA$} & $\omega_{e} / \mathrm{cm}^{-1}$ & $\omega_{e} x_{e} / \mathrm{cm}^{-1}$ & \multicolumn{1}{c}{$D_{e} / \mathrm{cm}^{-1}$} \\
\hline $\mathrm{Na}^{+} .{ }^{4} \mathrm{He}$ & $\mathbf{2 . 3 2 4}$ & $\mathbf{1 5 4 . 7}$ & $\mathbf{2 0 . 5}$ & $\mathbf{3 2 9 . 1}$ \\
$\mathrm{Na}^{+} .{ }^{20} \mathrm{Ne}$ & $\mathbf{2 . 4 7 2}$ & $\mathbf{1 0 6 . 6}$ & $\mathbf{6 . 5 6}$ & $\mathbf{5 1 3 . 8}$ \\
$\mathrm{Na}^{+} .{ }^{40} \mathrm{Ar}$ & $\mathbf{2 . 7 8 0}$ & $\mathbf{1 2 5 . 2}$ & $\mathbf{3 . 4 1}$ & $\mathbf{1 3 3 3 . 0}$ \\
$\mathrm{Na}^{+} .84 \mathrm{Kr}$ & $\mathbf{2 . 9 2 0}$ & $\mathbf{1 1 7 . 7}$ & $\mathbf{2 . 3 4}$ & $\mathbf{1 6 9 3 . 3}$ \\
& $3.50^{\mathrm{a}}$ & & & $1340^{\mathrm{a}}$ \\
& $2.89^{\mathrm{b}}$ & & & $1500^{\mathrm{b}}$ \\
& $2.77^{\mathrm{c}}$ & & & $1900^{\mathrm{c}}$ \\
& $2.85^{\mathrm{d}}$ & & & $1630^{\mathrm{d}}$ \\
& $2.87^{\mathrm{e}}$ & & & $1690^{\mathrm{e}}$ \\
& $2.71 \pm 0.10^{\mathrm{f}}$ & & & $2100 \pm 300^{\mathrm{f}}$ \\
& $2.87^{\mathrm{g}}$ & & & $1770^{\mathrm{g}}$ \\
$\mathrm{Na}^{+} .{ }^{132} \mathrm{Xe}$ & $\mathbf{3 . 1 0 4}$ & $\mathbf{1 1 8 . 5}$ & $\mathbf{1 . 7 9}$ & $\mathbf{2 1 8 4 . 1}$ \\
& $3.47^{\mathrm{a}}$ & & & $2280^{\mathrm{a}}$ \\
& $2.92^{\mathrm{c}}$ & & & $2300^{\mathrm{c}}$ \\
& $3.06^{\mathrm{d}}$ & & & $1940^{\mathrm{d}}$ \\
& $3.03^{\mathrm{e}}$ & & & $2090^{\mathrm{e}}$ \\
& $2.79 \pm 0.11^{\mathrm{f}}$ & $105^{\mathrm{f}}$ & $1.8^{\mathrm{f}}$ & $2900 \pm 500^{\mathrm{f}}$ \\
& $3.11^{\mathrm{g}}$ & & & $2080^{\mathrm{g}}$ \\
& $3.21^{\mathrm{h}}$ & & & $1690^{\mathrm{h}}$ \\
$\mathrm{Na}^{+} .{ }^{\mathrm{h}} 222 \mathrm{Rn}$ & $\mathbf{3 . 1 9 2}$ & $\mathbf{1 1 5 . 9}$ & $\mathbf{1 . 4 8}$ & $\mathbf{2 4 6 7 . 2}$ \\
\hline \hline
\end{tabular}

${ }^{\mathrm{a}}$ From Ref. 11.

${ }^{\mathrm{b}}$ From Ref. 8, model III.

${ }^{\mathrm{c}}$ From Ref. 10.

dFrom Ref. 9.

${ }^{\mathrm{e}}$ From Ref. 12.

f"Best" estimate I from Ref. 15

${ }^{\mathrm{g}}$ From Ref. 4.

${ }^{\mathrm{h}}$ From Ref. 16.

in the fit for $D_{4}$ and $D_{6}$ (see, e.g., Ref. 29); however, it has been noted by Ahmadi et al. ${ }^{30}$ that this can lead to significant error in the fitted potential. Although in Ref. 3 we were able to derive $D_{4}$ and $D_{6}$ from the long-range regions of the $\mathrm{Na}^{+} \cdot \mathrm{He}, \mathrm{Na}^{+} \cdot \mathrm{Ne}$ and $\mathrm{Na}^{+} \cdot$ Ar potentials, we noted that for $D_{6}$ in particular, a heuristic approach had to be taken. Regions of the potential energy curve were matched to Eq. (1) to obtain the smallest error, with no account being taken of the repulsive terms, damping factors, or higher $D_{n}$ terms. Subsequent detailed work on $\mathrm{Li}^{+} \cdot \mathrm{He}^{1}$, where the latter terms were considered, has led us to the conclusion that the fitting of $D_{6}$ (and other $D_{n}$ terms) requires very careful consideration, and we refrain from such fits in the present work. We did, however, confirm that the potentials at very large $R$ have a $-D_{4} / R^{4}$ dependence, and that the value of $D_{4}$ was consistent with well-established values for the polarizabilities of $\mathrm{He}-\mathrm{Ar}$, and with the values for $\mathrm{Kr}-\mathrm{Rn}$ calculated by ourselves $^{31}$ and others. Breckenridge and co-workers have considered the importance of the various contributions to $\mathrm{M}^{+} \cdot \operatorname{Rg}$ bonding. $6,32,33$

\section{A. Spectroscopy}

The derived rovibrational spectroscopic quantities are given in Tables II and III. The rotational energy levels for each vibrational level were fitted to the expression

$$
\begin{aligned}
E(v, J)= & E(v, 0)+B_{v} J(J+1)-D_{v} J^{2}(J+1)^{2} \\
& +H_{v} J^{3}(J+1)^{3} .
\end{aligned}
$$

TABLE III. Calculated rovibrational spectroscopic constants for ${ }^{23} \mathrm{Na}^{+}$

\begin{tabular}{|c|c|c|c|c|}
\hline$v$ & $E(v, 0)-E(0,0)$ & $B_{v} / \mathrm{cm}^{-1}$ & $D_{v} \mathrm{~cm}^{-1}$ & $H_{v} \mathrm{~cm}^{-1}$ \\
\hline \multicolumn{5}{|c|}{$\mathrm{Na}^{+} \cdot{ }^{4} \mathrm{He}$} \\
\hline 0 & 0 & 0.848 & $1.442 \times 10^{-4}$ & $5.611 \times 10^{-8}$ \\
\hline 1 & 113.71 & 0.702 & $2.137 \times 10^{-4}$ & $14.71 \times 10^{-8}$ \\
\hline 2 & 186.43 & 0.541 & $3.232 \times 10^{-4}$ & $36.02 \times 10^{-8}$ \\
\hline 3 & 226.88 & 0.380 & $4.623 \times 10^{-4}$ & $79.26 \times 10^{-8}$ \\
\hline \multicolumn{5}{|c|}{$\mathrm{Na}^{+} \cdot{ }^{20} \mathrm{Ne}$} \\
\hline 0 & 0 & 0.250 & $6.410 \times 10^{-6}$ & $3.947 \times 10^{-10}$ \\
\hline 1 & 93.56 & 0.233 & $7.512 \times 10^{-6}$ & $5.950 \times 10^{-10}$ \\
\hline 2 & 173.70 & 0.215 & $8.904 \times 10^{-6}$ & $8.983 \times 10^{-10}$ \\
\hline 3 & 241.06 & 0.197 & $10.63 \times 10^{-6}$ & $13.43 \times 10^{-10}$ \\
\hline \multicolumn{5}{|c|}{$\mathrm{Na}^{+} .{ }^{40} \mathrm{Ar}$} \\
\hline 0 & 0 & 0.147 & $8.763 \times 10^{-7}$ & $9.798 \times 10^{-12}$ \\
\hline 1 & 118.38 & 0.143 & $9.303 \times 10^{-7}$ & $11.78 \times 10^{-12}$ \\
\hline 2 & 229.90 & 0.139 & $9.906 \times 10^{-7}$ & $14.19 \times 10^{-12}$ \\
\hline 3 & 334.63 & 0.134 & $10.58 \times 10^{-7}$ & $17.14 \times 10^{-12}$ \\
\hline \multicolumn{5}{|c|}{$\mathrm{Na}^{+} .{ }^{84} \mathrm{Kr}$} \\
\hline 0 & 0 & 0.108 & $3.873 \times 10^{-7}$ & $2.337 \times 10^{-12}$ \\
\hline 1 & 113.022 & 0.106 & $4.035 \times 10^{-7}$ & $2.675 \times 10^{-12}$ \\
\hline 2 & 221.352 & 0.104 & $4.210 \times 10^{-7}$ & $3.066 \times 10^{-12}$ \\
\hline 3 & 325.007 & 0.101 & $4.401 \times 10^{-7}$ & $3.520 \times 10^{-12}$ \\
\hline \multicolumn{5}{|c|}{$\mathrm{Na}^{+} \cdot{ }^{132} \mathrm{Xe}$} \\
\hline 0 & 0 & $8.864 \times 10^{-2}$ & $2.062 \times 10^{-7}$ & $7.234 \times 10^{-13}$ \\
\hline 1 & 114.902 & $8.722 \times 10^{-2}$ & $2.124 \times 10^{-7}$ & $8.056 \times 10^{-13}$ \\
\hline 2 & 226.222 & $8.577 \times 10^{-2}$ & $2.190 \times 10^{-7}$ & $8.979 \times 10^{-13}$ \\
\hline 3 & 333.958 & $8.430 \times 10^{-2}$ & $2.261 \times 10^{-7}$ & $10.023 \times 10^{-13}$ \\
\hline \multicolumn{5}{|c|}{$\mathrm{Na}^{+} .{ }^{222} \mathrm{Rn}$} \\
\hline 0 & 0 & $7.892 \times 10^{-2}$ & $1.511 \times 10^{-7}$ & $3.887 \times 10^{-13}$ \\
\hline 1 & 112.952 & $7.782 \times 10^{-2}$ & $1.547 \times 10^{-7}$ & $4.268 \times 10^{-13}$ \\
\hline 2 & 222.943 & $7.671 \times 10^{-2}$ & $1.584 \times 10^{-7}$ & $4.691 \times 10^{-13}$ \\
\hline 3 & 329.966 & $7.559 \times 10^{-2}$ & $1.625 \times 10^{-7}$ & $5.158 \times 10^{-13}$ \\
\hline
\end{tabular}
-Rg. $E(v, J)=E(v, 0)+B_{v} J(J+1)-D_{v} J^{2}(J+1)^{2}+H_{v} J^{3}(J+1)^{3}$.

Note that in Ref. 3 there were some errors in the reported value of the exponent for the centrifugal distortion terms for $\mathrm{Na}^{+} \cdot \mathrm{Ne}$ and $\mathrm{Na}^{+} \cdot \mathrm{Ar}$, and so we present the whole set of correct results in the present work for clarity. The explicit vibrational energy levels are given in Table III for all six complexes, and the derived $\omega_{e}$ and $\omega_{e} x_{e}$ values are given in Table II; for all except $\mathrm{Na}^{+} \cdot \mathrm{He}$, these were obtained from a fit of the four vibrational energies listed in Table III to the two-term Morse potential energy function (the higher anharmonicity of $\mathrm{Na}^{+} \cdot \mathrm{He}$ meant that such a fit had significant error, and so only the two lowest energy levels were used in this case).

We only include the $\mathrm{Na}^{+} \cdot \mathrm{He}, \mathrm{Na}^{+} \cdot \mathrm{Ne}$, and $\mathrm{Na}^{+} \cdot \mathrm{Ar}$ results here for comparison and completeness; the spectroscopic results and their comparison with previous studies have been described in detail in Ref. 3, where good agreement with the most-recent, high-level calculations was noted.

Information on $\mathrm{Na}^{+} \cdot \mathrm{Kr}$ and $\mathrm{Na}^{+} \cdot \mathrm{Xe}$ has been obtained indirectly from ion beam scattering studies, ${ }^{11,12}$ as well as from ion transport data. ${ }^{4,5}$ Theoretical studies have been undertaken, but these seem to have been limited to electron gas calculations ${ }^{9}$ and some recent Coupled Electron Pair Approximation (CEPA) calculations. ${ }^{16}$ No previous studies of $\mathrm{Na}^{+} \cdot \mathrm{Rn}$ have been reported to our knowledge. The values for the internuclear separations and the dissociation energies obtained in the previous studies are given in Table II, to- 
gether with the values derived in the present work. It may be seen that, on the whole, there is reasonable agreement between our results and the previous experimental values, although the bond lengths derived from the earlier electron beam scattering experiments ${ }^{11}$ seem to be too long. One exception is that the dissociation energy for $\mathrm{Na}^{+} \cdot \mathrm{Kr}$ obtained experimentally appears to be too small-perhaps this is not surprising as beam studies generally probe the repulsive region of the potential, rather than the attractive part: indeed, no information on the attractive regions of the lighter $\mathrm{Na}^{+}$ - Rg systems could be obtained, ${ }^{11}$ owing to the insensitivity of the experiment to this part of the potential. The quantities derived from the ion transport studies are in relatively good agreement with the results obtained herein, which is likely to be due to the fact that the potentials have been derived from a wide range of $E / N$ data, which will be sensitive to both the attractive and repulsive regions of the potential-statistical comparisons between these potentials will be made below when considering the transport data.

Looking at the theoretical studies, the (modified) electron gas model of Waldman and Gordon ${ }^{9}$ performs fairly well, giving values for both the internuclear separation and the well depth that are close to the values derived from the present work for both $\mathrm{Na}^{+} \cdot \mathrm{Kr}$ and $\mathrm{Na}^{+} \cdot$ Xe (see Table II). The only other $a b$ initio study is that of Freitag et al. ${ }^{16}$ who only considered $\mathrm{Na}^{+} \cdot \mathrm{Xe}$ at the CEPA level of theory. Their bond length is in good agreement with the present value, but the well depth is a little shallow: this probably results from a combination of the omission of some of the correlation energy, as well as the use of a relatively small basis set. Only a small basis set could be used in that work, both because of computational limitations at that time, but also as no ECP was employed, and so the number of valence basis functions was limited. It is especially important in these species to be able to describe the distortion of the $\mathrm{Rg}$ valence orbitals along the internuclear direction, as caused by the charge/ induced-dipole interaction. This in turn means that one must be able to describe the polarization of the Rg atom well; we showed in Ref. 31, and for $\mathrm{Li}^{+} \cdot \operatorname{Rg}$ in Ref. 2, that the types of basis sets we employ herein are able to describe these effects well.

There appears only to have been one previous report of a vibrational frequency for these species-for $\mathrm{Na}^{+} \cdot$ Xe in Ref. 16. The values for both $\omega_{e}$ and $\omega_{e} x_{e}$ are in good agreement with our derived values (see Table II).

We conclude that we have produced a reliable set of potential energy parameters for these species; in a number of cases, these values are the first ones reported.

Considering the set of values in Table II for the $\mathrm{Na}^{+}$ - $\operatorname{Rg}$ series, we see that, as expected, the dissociation energy increases as we descend the Rg group, in line with the increasing polarizability of $\mathrm{Rg}$ (Ref. 31) - a trend also observed in our work on $\mathrm{Li}^{+} \cdot \mathrm{Rg}$ (Ref. 2) and $\mathrm{Rg} \cdot \mathrm{NO}^{+}$(Refs. 34 and 35). Interestingly, the vibrational frequencies do not follow a monotonically increasing trend, and such a variation is also seen for other $\mathrm{M}^{+} \cdot \operatorname{Rg}$ species, ${ }^{2,6}$ it probably represents a subtle balance between the increasing attraction (charge/induced dipole) and increasing repulsive (electronelectron repulsion) terms.

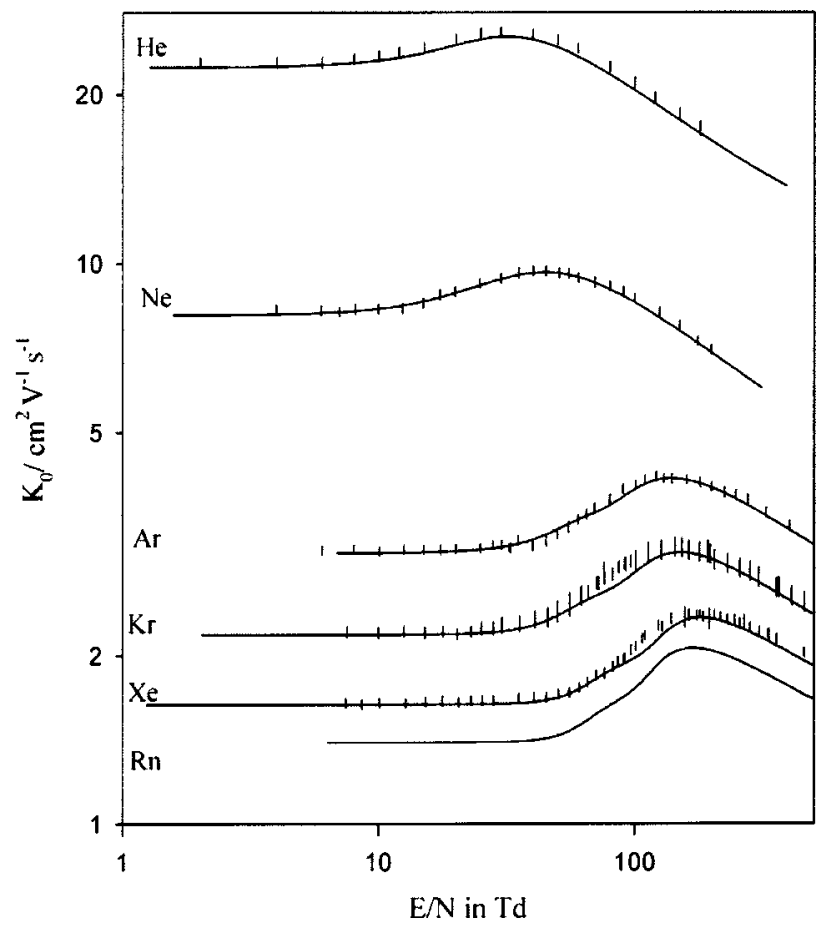

FIG. 1. Log-log plots of the standard mobility, $K_{o}$ in $\mathrm{cm}^{2} \mathrm{~V}^{-1} \mathrm{~s}^{-1}$, as a function of the reduced field strength, $E / N$ in $\mathrm{Td}\left(1 \mathrm{Td}=10^{-21} \mathrm{~V} \mathrm{~m}^{2}\right)$, for $\mathrm{Na}^{+}$in the rare gases. The temperature is $300 \mathrm{~K}$ for all gases except Xe, for which $T=303 \mathrm{~K}$. The curves are those calculated in the present work-see Tables IV-VIII for statistical analyses. The lines are experimental values from Refs. 37 and 38, whose length represents the maximum estimated experimental errors. The small wobbles in the calculated $K_{o}$ curves are artifacts- see the text.

\section{B. Transport data}

We have calculated the transport coefficients at a large number of $E / N$ values and at many gas temperatures for each of the six $\mathrm{Na}^{+} \cdot \mathrm{Rg}$ systems. The number of results is too large to list here or even to show graphically; we have placed them in the gaseous ion transport database maintained at Chatham College. ${ }^{36}$ As a guide to the eye, we present in Fig. 1 the calculated standard mobilities and the experimental results from the Georgia Tech group. ${ }^{37,38}$ As noted above, there are very slight "wobbles" in the $K_{o}$ curves at intermediate $E / N$ caused by a slower convergence in these regions, which we did not attempt to overcome with more extensive computations.

In previous work, ${ }^{39,40}$ we have reported the average percentage difference and standard deviation between calculated and measured transport coefficients. More recently, ${ }^{28}$ we introduced statistical quantities, $\delta$ and $\chi$, to measure the differences between calculated and measured transport coefficients while taking into account the estimated errors in each quantity. If the experimental and calculated errors are the same at all $E / N$, then $\delta$ is the ratio of the average percentage difference to the maximum combined percentage difference expected, while $\chi$ is the ratio of the standard deviation of the percentage differences to the root-mean-square of the maximum combined percentage deviations expected. A positive value of $\delta$ indicates that the data lie above the calculated values, and vice versa. Values of the absolute value of $\delta$ that are substantially lower (alternatively, higher) than 1 indicate 
TABLE IV. Statistical comparison of calculated and experimental transport data for $\mathrm{Na}^{+}$ions in $\mathrm{He}$ gas.

\begin{tabular}{|c|c|c|c|c|c|c|c|c|c|c|c|c|}
\hline \multirow[b]{2}{*}{ Data type } & \multirow{2}{*}{$\begin{array}{c}\text { Range of } \\
E / N^{\mathrm{a}}\end{array}$} & \multirow[b]{2}{*}{ Accuracy $^{\mathrm{b}}$} & \multirow{2}{*}{$\begin{array}{l}\text { No. of } \\
\text { Points }\end{array}$} & \multicolumn{3}{|c|}{ Ref. 5} & \multicolumn{3}{|c|}{ Ref. 43} & \multicolumn{3}{|c|}{ This work/Ref. 3} \\
\hline & & & & Precision $^{\mathrm{c}}$ & $\delta$ & $\chi$ & Precision $^{c}$ & $\delta$ & $\chi$ & Precision $^{c}$ & $\delta$ & $\chi$ \\
\hline \multicolumn{13}{|l|}{$K_{o} 300 \mathrm{~K}$} \\
\hline & $1-10$ & 2 & 14 & 0.1 & -1.300 & 1.316 & 0.1 & -1.548 & 1.554 & 0.1 & 0.544 & 0.585 \\
\hline \multirow[t]{3}{*}{ Ref. 37} & $10-50$ & 2 & 10 & 0.1 & 0.089 & 0.704 & 0.1 & -0.431 & 0.756 & 0.1 & 1.164 & 1.175 \\
\hline & $50-174$ & 2 & 5 & 0.1 & 0.906 & 0.995 & 0.1 & 0.555 & 0.606 & 0.1 & 1.306 & 1.327 \\
\hline & $1-174$ & & 29 & & -0.44 & 1.09 & & -0.80 & 1.19 & & 0.89 & 0.97 \\
\hline \multirow[t]{2}{*}{$D_{\|} 300 \mathrm{~K}$} & $1-10$ & 5 & 14 & 1 & 1.509 & 1.539 & 1 & 1.045 & 1.087 & 1 & 2.355 & 2.378 \\
\hline & $10-50$ & 5 & 10 & 1 & 2.973 & 3.446 & 1 & 2.595 & 3.248 & 1 & 3.069 & 3.312 \\
\hline \multirow[t]{2}{*}{ Ref. 41} & $50-174$ & 5 & 5 & 1 & 3.223 & 3.456 & 1 & 3.228 & 3.467 & 1 & 4.216 & 4.324 \\
\hline & $1-174$ & & 29 & & 2.31 & 2.70 & & 1.96 & 2.51 & & 2.92 & 3.12 \\
\hline \multirow{2}{*}{$K_{o} 309 \mathrm{~K}$} & $1-10$ & 3 & 14 & 0.1 & -0.738 & 0.774 & 0.1 & -1.407 & 1.426 & 0.1 & 0.499 & 0.555 \\
\hline & $10-50$ & 3 & 21 & 0.1 & -0.213 & 0.703 & 0.1 & -0.730 & 1.046 & 0.1 & 0.584 & 0.811 \\
\hline \multirow[t]{2}{*}{ Ref. 40} & $50-139$ & 3 & 9 & 0.1 & 0.032 & 0.488 & 0.1 & -0.071 & 0.465 & 0.1 & 0.198 & 0.498 \\
\hline & $2-125$ & & 44 & & -0.33 & 0.69 & & -0.81 & 1.10 & & 0.48 & 0.68 \\
\hline
\end{tabular}

${ }^{\mathrm{a} I n}$ units of $\mathrm{Td}$.

${ }^{\mathrm{b}}$ Accuracy of experiment $(\%)$.

${ }^{\mathrm{c}}$ Precision of calculations (\%)

that there is substantial agreement (disagreement) between the calculated and measured values, on average. Values of $\chi$ that are not much larger than $|\delta|$ indicate that there is little scatter in the experimental data, and that the agreement between the calculated and measured values is uniform over all values of $E / N$, while values of $\chi$ substantially greater than $|\delta|$ indicate that at least one of these factors is not true. The statistical comparisons are performed at low, intermediate, and high $E / N$ regions, using a larger estimate of the calculation errors at intermediate $E / N$ in order to prevent the slight wobble from influencing our conclusions.

Tables IV-VIII give the values of $\delta$ and $\chi$ obtained for the transport properties of $\mathrm{Na}^{+}$ions in the first five rare gases. There are no data to which we can compare the present $\mathrm{Na}^{+} / \mathrm{Rn}$ results.

\section{1. $\mathrm{Na}^{+} \cdot \mathrm{He}$}

Ion scattering and transport experiments do not provide information on shallow potentials unless the relative kinetic energy or gas temperature is very low. Since the well depth for the $\mathrm{Na}^{+} \cdot \mathrm{He}$ interaction is $40.8 \mathrm{meV}$ (equivalent to 474 $\mathrm{K})$, we expect our ab initio potential for He to be more accurate near and beyond the minimum position (4.4 bohr or 2.3 angstrom) than are potentials derived from inverting scattering or mobility data.

TABLE V. Statistical comparison of calculated and experimental transport data for $\mathrm{Na}^{+}$ions in $\mathrm{Ne}$ gas.

\begin{tabular}{|c|c|c|c|c|c|c|c|c|c|}
\hline \multirow[b]{2}{*}{ Data type } & \multirow{2}{*}{$\begin{array}{c}\text { Range of } \\
E / N^{\mathrm{a}}\end{array}$} & \multirow[b]{2}{*}{ Accuracy $^{\mathrm{b}}$} & \multirow{2}{*}{$\begin{array}{l}\text { No. of } \\
\text { points }\end{array}$} & \multicolumn{3}{|c|}{ Ref. 5} & \multicolumn{3}{|c|}{ This work/Ref. 3} \\
\hline & & & & Precision $^{\mathrm{c}}$ & $\delta$ & $\chi$ & Precision $^{\mathrm{c}}$ & $\delta$ & $\chi$ \\
\hline \multirow[t]{2}{*}{$K_{o} 300 \mathrm{~K}$} & $4-15$ & 2 & 7 & 0.1 & 0.233 & 0.491 & 0.1 & 0.144 & 0.488 \\
\hline & $15-65$ & 2 & 10 & 0.3 & 0.327 & 0.424 & 0.3 & 0.244 & 0.311 \\
\hline \multirow{2}{*}{ Ref. 37} & $65-200$ & 2 & 8 & 0.1 & 0.061 & 0.403 & 0.1 & 0.739 & 0.806 \\
\hline & $4-200$ & & 25 & & 0.22 & 0.44 & & 0.37 & 0.56 \\
\hline \multirow{2}{*}{$D_{\|} 300 \mathrm{~K}$} & $4-15$ & 5 & 7 & 0.1 & 0.640 & 0.815 & 1 & 0.540 & 0.768 \\
\hline & $15-65$ & 5 & 10 & 0.3 & 2.051 & 2.132 & 3 & 2.226 & 2.450 \\
\hline \multirow[t]{2}{*}{ Ref. 41} & $65-200$ & 5 & 8 & 0.1 & 1.662 & 1.851 & 1 & 2.873 & 2.910 \\
\hline & $4-200$ & & 25 & & 1.53 & 1.76 & & 1.96 & 2.30 \\
\hline \multirow[t]{2}{*}{$K_{o} 311 \mathrm{~K}$} & $2-15$ & 0.85 & 24 & 0.1 & -2.457 & 2.505 & 0.1 & -2.706 & 2.740 \\
\hline & $15-65$ & 0.85 & 24 & 0.3 & -1.590 & 1.611 & 0.3 & -1.827 & 1.870 \\
\hline \multirow[t]{2}{*}{ Ref. 46} & $65-125$ & 0.85 & 5 & 0.1 & -2.007 & 2.064 & 0.1 & -0.921 & 1.001 \\
\hline & $2-125$ & & 53 & & -2.02 & 2.10 & & -2.14 & 2.25 \\
\hline \multirow[t]{2}{*}{$D_{\|} 311 \mathrm{~K}$} & $2-15$ & 18.5 & 24 & 1 & 0.540 & 0.930 & 1 & 0.509 & 0.920 \\
\hline & $15-65$ & 7 & 24 & 3 & -0.194 & 0.719 & 3 & 0.046 & 0.591 \\
\hline \multirow[t]{2}{*}{ Ref. 46} & $65-125$ & 7 & 5 & 1 & -0.637 & 1.271 & 1 & 0.154 & 1.118 \\
\hline & $2-125$ & & 53 & & 0.10 & 0.88 & & 0.27 & 0.81 \\
\hline \multirow[t]{2}{*}{$D_{\perp} 295 \mathrm{~K}$} & $10-65$ & 3 & 6 & 3 & 0.052 & 0.176 & 3 & 0.118 & 0.181 \\
\hline & $65-200$ & 3 & 14 & 1 & -1.542 & 1.698 & 1 & -0.514 & 0.764 \\
\hline Ref. 47 & $10-200$ & & 20 & & -1.06 & 1.42 & & -0.32 & 0.65 \\
\hline
\end{tabular}

${ }^{\mathrm{a} I n}$ units of Td.

${ }^{\mathrm{b}}$ Accuracy of experiment $(\%)$.

${ }^{\mathrm{c}}$ Precision of calculations $(\%)$. 
TABLE VI. Statistical comparison of calculated and experimental transport data for $\mathrm{Na}^{+}$ions in Ar gas.

\begin{tabular}{|c|c|c|c|c|c|c|c|c|c|}
\hline \multirow[b]{2}{*}{ Data type } & \multirow{2}{*}{$\begin{array}{c}\text { Range of } \\
E / N^{\mathrm{a}}\end{array}$} & \multirow[b]{2}{*}{ Accuracy $^{\mathrm{b}}$} & \multirow{2}{*}{$\begin{array}{l}\text { No. of } \\
\text { points }\end{array}$} & \multicolumn{3}{|c|}{ Ref. 5} & \multicolumn{3}{|c|}{ This work/Ref. 3} \\
\hline & & & & Precision $^{c}$ & $\delta$ & $\chi$ & Precision $^{\mathrm{c}}$ & $\delta$ & $\chi$ \\
\hline \multirow[t]{2}{*}{$K_{o} 300 \mathrm{~K}$} & $6-40$ & 2 & 12 & 0.3 & 0.531 & 0.595 & 0.1 & 0.435 & 0.528 \\
\hline & $40-125$ & 2 & 12 & 0.9 & 0.860 & 1.305 & 0.3 & 0.166 & 0.865 \\
\hline \multirow[t]{3}{*}{ Ref. 37} & $125-190$ & 2 & 4 & 2.0 & 0.446 & 0.515 & 0.3 & 0.095 & 0.136 \\
\hline & $190-502$ & 2 & 7 & 0.9 & -0.187 & 0.327 & 0.3 & 0.577 & 0.694 \\
\hline & $6-502$ & & 35 & & 0.49 & 0.87 & & 0.33 & 0.67 \\
\hline \multirow[t]{2}{*}{$D_{\|} 300 \mathrm{~K}$} & $6-40$ & 5 & 12 & 3 & 1.223 & 1.340 & 1 & 1.238 & 1.287 \\
\hline & $120-190$ & 5 & 5 & 20 & 0.809 & 0.873 & 3 & 1.980 & 2.046 \\
\hline \multirow[t]{2}{*}{ Ref. 41} & $190-502$ & 5 & 7 & 9 & 0.550 & 0.578 & 1 & 2.905 & 2.985 \\
\hline & $6-502$ & & 24 & & 0.94 & 1.07 & & 1.88 & 2.07 \\
\hline \multirow[t]{2}{*}{$K_{o} 303 \mathrm{~K}$} & $42-125$ & 3 & 8 & 0.9 & 1.979 & 2.033 & 0.1 & 1.784 & 1.857 \\
\hline & $125-190$ & 3 & 4 & 2.0 & 0.462 & 0.495 & 0.3 & 0.825 & 0.868 \\
\hline \multirow[t]{2}{*}{ Ref. 48} & $190-339$ & 3 & 6 & 0.9 & -0.396 & 0.784 & 0.1 & 0.013 & 0.854 \\
\hline & $42-339$ & & 18 & & 0.85 & 1.45 & & 0.98 & 1.39 \\
\hline \multirow[t]{2}{*}{$K_{o} 314 \mathrm{~K}$} & $6-40$ & 0.85 & 17 & 0.3 & -0.731 & 0.807 & 0.1 & -1.375 & 1.398 \\
\hline & $40-125$ & 0.85 & 11 & 0.9 & 0.543 & 0.867 & 0.3 & -0.979 & 1.273 \\
\hline \multirow[t]{3}{*}{ Ref. 46} & $125-190$ & 0.85 & 6 & 2.0 & -0.705 & 0.722 & 0.3 & -1.536 & 1.571 \\
\hline & $190-409$ & 0.85 & 6 & 0.9 & -1.404 & 1.422 & 0.1 & -0.601 & 0.816 \\
\hline & $6-409$ & & 40 & & -0.48 & 0.93 & & -1.17 & 1.32 \\
\hline \multirow[t]{2}{*}{$D_{\|} 314 \mathrm{~K}$} & $6-40$ & 18.5 & 17 & 3 & 1.180 & 1.376 & 1 & 1.213 & 1.480 \\
\hline & $125-190$ & 7.0 & 6 & 20 & 0.004 & 0.307 & 3 & 0.501 & 0.725 \\
\hline \multirow[t]{2}{*}{ Ref. 46} & $190-409$ & 18.5 & 6 & 9 & -0.302 & 0.354 & 1 & -0.079 & 0.272 \\
\hline & $6-409$ & & 29 & & 0.63 & 1.07 & & 0.80 & 1.19 \\
\hline \multirow[t]{2}{*}{$D_{\perp} 297 \mathrm{~K}$} & $10-40$ & 3 & 6 & 1 & 0.445 & 0.504 & 1 & 0.204 & 0.273 \\
\hline & $40-125$ & 3 & 9 & 3 & -1.751 & 2.171 & 3 & -1.987 & 2.247 \\
\hline \multirow[t]{3}{*}{ Ref. 47} & $125-190$ & 3 & 3 & 3 & -4.314 & 4.327 & 3 & -2.613 & 2.627 \\
\hline & $190-260$ & 3 & 4 & 1 & -4.798 & 4.798 & 1 & -4.132 & 4.133 \\
\hline & $10-260$ & & 22 & & -2.06 & 2.96 & & -1.12 & 2.48 \\
\hline
\end{tabular}

${ }^{\mathrm{a}}$ In units of $\mathrm{Td}$.

${ }^{\mathrm{b}}$ Accuracy of experiment $(\%)$.

${ }^{\mathrm{c}}$ Precision of calculations $(\%)$.

In Ref. 2, we noted that $a b$ initio curves at very short $R$ may suffer from the effects of BSSE, which is difficult to correct for as the basis functions overlap more, and the moieties in the counterpoise correction become less defined. Fortunately, the BSSE becomes a smaller percentage of the total energy as the internuclear separation increases, and our $\mathrm{Na}^{+} \cdot \mathrm{He}$ potential gives scattering results that are in good agreement with experiment.

The transport data from Refs. 37, 41, and 42 are compared in Table IV to the present calculated results and to the

TABLE VII. Statistical comparison of calculated and experimental transport data for $\mathrm{Na}^{+}$ions in $\mathrm{Kr}$ gas.

\begin{tabular}{|c|c|c|c|c|c|c|c|c|c|}
\hline \multirow[b]{2}{*}{ Data type } & \multirow{2}{*}{$\begin{array}{c}\text { Range of } \\
E / N^{\mathrm{a}}\end{array}$} & \multirow[b]{2}{*}{ Accuracy $^{b}$} & \multirow{2}{*}{$\begin{array}{l}\text { No. of } \\
\text { points }\end{array}$} & \multicolumn{3}{|c|}{ Ref. 5} & \multicolumn{3}{|c|}{ This work } \\
\hline & & & & Precision $^{\mathrm{c}}$ & $\delta$ & $\chi$ & Precision $^{\mathrm{c}}$ & $\delta$ & $\chi$ \\
\hline \multirow[t]{2}{*}{$K_{o} 300 \mathrm{~K}$} & $7-40$ & 2.5 & 11 & 0.2 & -0.142 & 0.296 & 0.1 & 0.482 & 0.549 \\
\hline & $40-100$ & 2.5 & 15 & 2 & 0.540 & 0.745 & 1 & 1.376 & 1.546 \\
\hline \multirow[t]{3}{*}{ Ref. 38} & $100-115$ & 4 & 2 & 2 & 0.713 & 0.713 & 1 & 0.908 & 0.909 \\
\hline & $115-515$ & 4 & 18 & 0.2 & 0.528 & 0.565 & 0.1 & 0.550 & 0.579 \\
\hline & $7-515$ & & 46 & & 0.38 & 0.59 & & 0.82 & 1.01 \\
\hline \multirow[t]{2}{*}{$D_{\|} 300 \mathrm{~K}$} & $7-40$ & 5.5 & 11 & 2 & -0.166 & 0.728 & 1 & 0.121 & 0.887 \\
\hline & $160-515$ & 10 & 15 & 2 & 1.053 & 1.232 & 1 & 1.223 & 1.414 \\
\hline Ref. 38 & $7-515$ & & 26 & & 0.54 & 1.05 & & 0.76 & 1.22 \\
\hline \multirow[t]{2}{*}{$D_{\perp} 295 \mathrm{~K}$} & $10-45$ & 2 & 5 & 1 & -0.567 & 0.724 & 1 & -0.405 & 0.599 \\
\hline & $45-115$ & 2 & 6 & 3 & -1.238 & 1.425 & 3 & -1.132 & 1.345 \\
\hline \multirow[t]{2}{*}{ Ref. 45} & $115-500$ & 2 & 9 & 1 & -0.346 & 0.460 & 1 & -0.326 & 0.395 \\
\hline & $10-500$ & & 20 & & -0.67 & 0.91 & & -0.59 & 0.84 \\
\hline \multirow[t]{2}{*}{$D_{\perp} 303 \mathrm{~K}$} & $5-42$ & 3 & 8 & 1 & 0.192 & 0.224 & 1 & 0.326 & 0.365 \\
\hline & $42-115$ & 3 & 10 & 3 & -0.971 & 1.154 & 3 & -0.888 & 1.102 \\
\hline \multirow[t]{2}{*}{ Ref. 50} & $15-500$ & 3 & 19 & 1 & -0.329 & 0.459 & 1 & -0.310 & 0.462 \\
\hline & $5-500$ & & 37 & & -0.39 & 0.69 & & -0.33 & 0.68 \\
\hline
\end{tabular}

${ }^{\mathrm{a}}$ In units of Td.

${ }^{\mathrm{b}}$ Accuracy of experiment (\%).

${ }^{\mathrm{c}}$ Precision of calculations (\%). 
TABLE VIII. Statistical comparison of calculated and experimental transport data for $\mathrm{Na}^{+}$ions in Xe gas.

\begin{tabular}{|c|c|c|c|c|c|c|c|c|c|}
\hline \multirow[b]{2}{*}{ Data type } & \multirow{2}{*}{$\begin{array}{c}\text { Range of } \\
E / N^{\mathrm{a}}\end{array}$} & \multirow[b]{2}{*}{ Accuracy $^{\mathrm{b}}$} & \multirow{2}{*}{$\begin{array}{l}\text { No. of } \\
\text { points }\end{array}$} & \multicolumn{3}{|c|}{ Ref. 5} & \multicolumn{3}{|c|}{ This work } \\
\hline & & & & Precision $^{c}$ & $\delta$ & $\chi$ & Precision $^{\mathrm{c}}$ & $\delta$ & $\chi$ \\
\hline \multirow[t]{2}{*}{$K_{o} 303 \mathrm{~K}$} & $7-42$ & 2 & 13 & 0.1 & -0.337 & 0.425 & 0.1 & 0.648 & 0.722 \\
\hline & $42-155$ & 2 & 17 & 1 & -0.064 & 0.710 & 1 & 0.903 & 1.132 \\
\hline \multirow[t]{2}{*}{ Ref. 38} & $115-509$ & 2 & 18 & 0.1 & 1.791 & 2.078 & 0.1 & 1.006 & 1.153 \\
\hline & $7-509$ & & 48 & & 0.56 & 1.36 & & 0.87 & 1.05 \\
\hline \multirow[t]{2}{*}{$N D_{\|} 303 \mathrm{~K}$} & $12-42$ & 5 & 10 & 1 & 0.934 & 1.886 & 1 & 1.585 & 2.301 \\
\hline & $42-155$ & 5 & 17 & 3 & -0.129 & 1.641 & 3 & 0.213 & 1.300 \\
\hline \multirow[t]{2}{*}{ Ref. 38} & $155-509$ & 5 & 18 & 1 & 3.648 & 3.792 & 1 & 1.967 & 2.152 \\
\hline & $7-509$ & & 45 & & 1.62 & 2.75 & & 1.22 & 1.92 \\
\hline \multirow[t]{2}{*}{$K_{o} 300 \mathrm{~K}$} & $7-42$ & 5 & 4 & 0.1 & -0.305 & 0.307 & 0.1 & 0.110 & 0.133 \\
\hline & $42-155$ & 5 & 4 & 1 & -0.066 & 0.312 & 1 & 0.340 & 0.435 \\
\hline \multirow[t]{2}{*}{ Ref. 52} & $155-500$ & 5 & 5 & 0.1 & 0.876 & 0.934 & 0.1 & 0.395 & 0.420 \\
\hline & $7-500$ & & 13 & & 0.223 & 0.628 & & 0.290 & 0.496 \\
\hline \multirow[t]{2}{*}{$D_{\perp} / K 303 \mathrm{~K}$} & $5-42$ & 3.5 & 8 & 1 & -0.174 & 0.371 & 1 & -0.005 & 0.193 \\
\hline & $42-155$ & 3.5 & 15 & 3 & -0.694 & 0.886 & 3 & -0.299 & 0.485 \\
\hline \multirow[t]{2}{*}{ Ref. 51} & $155-440$ & 3.5 & 17 & 1 & -0.281 & 0.396 & 1 & -1.171 & 1.309 \\
\hline & $5-440$ & & 40 & & -0.41 & 0.62 & & -0.61 & 0.91 \\
\hline
\end{tabular}

${ }^{\mathrm{a}}$ In units of $\mathrm{Td}$.

${ }^{\mathrm{b}}$ Accuracy of experiment $(\%)$.

${ }^{\mathrm{c}}$ Precision of calculations $(\%)$.

results calculated from the potentials of Refs. 5 and 43. (Note that additional results that have been calculated from the potential in Ref. 5 are given in Ref. 44). The mobility data from Refs. 37 and 42 are consistent with all three potentials, with the best agreement being found for the present potential. This is a somewhat surprising result since the model potential in Ref. 5 was derived from inverting the mobility data.

As may be seen from Table IV, the diffusion data from Ref. 41 are not consistent with any of the potentials, since $\delta>1$ for all of the potentials and the disagreement is outside the cited range. We suspect that these data are not as accurate as claimed by the experiments, for reasons discussed in Ref. 45.

\section{2. $\mathrm{Na}^{+} \cdot \mathrm{Ne}$}

The transport data from Refs. 37, 41, 46, and 47 are compared in Table $\mathrm{V}$ with values calculated from the present potential and those derived from the potential of Ref. 5. The mobility data from Ref. 46 are not consistent with either potential, whereas the other data are, suggesting that the cited error of $0.85 \%$ in Ref. 46 is optimistic. Although the diffusion data from Ref. 46 are consistent with the potentials and the other experimental data, this is probably only because of the large error bars claimed for the data. In contrast to $\mathrm{Na}^{+} \cdot \mathrm{He}$, this time the results from the potential from Ref. 5 are in slightly better agreement with the data than those from the present work: this is as expected as the model potential in Ref. 5 was derived from the experimental data.

\section{3. $\mathrm{Na}^{+} \cdot \mathrm{Ar}$}

The transport data from Refs. 37, 41, 46, 47, and 48 are compared in Table VI to the present results and those derived from the potential of Ref. 5 . As with $\mathrm{Na}^{+} \cdot \mathrm{He}$, but in contrast to $\mathrm{Na}^{+} \cdot \mathrm{Ne}$, the present potential fits the mobility data from Ref. 37 slightly better than that of Ref. 5-again an unex- pected result. The mobility data from Ref. 48 are inconsistent with the calculated values at low $E / N$, suggesting that the cited accuracy is too small; however, at high $E / N$ the agreement is much better. The mobility data from Ref. 46 are slightly in disagreement with the calculated values, suggesting that the cited error is a little on the low side.

The diffusion data from Ref. 48 have such large error bars that they encompass the results calculated from both potentials, and hence cannot discriminate between the potentials. The $D_{\perp} / K$ data from Ref. 47 are certainly in error above $40 \mathrm{Td}$. With regard to the diffusion data from Ref. 43, the potential from Ref. 5 is close to being consistent with the data, whereas the present potential is not. This is surprising because it is the reverse of the situation for the mobility and because the raw data used in both cases $^{37,40}$ were from the same experiments. One possibility for this disagreement would be that insufficient analysis ${ }^{49}$ of the raw data makes the cited errors too small, especially for the diffusion data.

\section{4. $\mathrm{Na}^{+} \cdot \mathrm{Kr}$}

The transport data from Refs. 38, 45, and 50 are compared in Table VII to the present calculated results and those derived from the potential of Ref. 5. With the possible exception of the $D_{\perp} / K$ data from Ref. 45, the potential from Ref. 5 appears to represent the available data better than the present potential. Since the potential from Ref. 5 was derived from the data in Ref. 38, this merely suggests that all of the experimental data are in agreement.

\section{5. $\mathrm{Na}^{+}$in $\mathrm{Xe}$}

The transport data from Refs. 38 and 51 and the smoothed data from Ref. 52 are compared in Table VIII to the present calculated results and those derived from the potential of Ref. 5. At low $E / N$ the potential from Ref. 5 represents the data from Refs. 38 and 52 better then the present potential, but the reverse is true for high $E / N$. Both 
potentials are more consistent with the data from Refs. 51 and 52 than the data from Ref. 38, suggesting that the errors in the latter are not as small as claimed-a conclusion consistent with the larger-than-usual errors cited for these data in Ref. 52.

\section{SUMMARY AND CONCLUDING REMARKS}

The potential energy curves presented for the six $\mathrm{Na}^{+}$ - $\mathrm{Rg}$ species, in the present work and in Ref. 3, are either the most accurate or the only $a b$ initio results available for these species. The level of theory employed and the large valence basis sets used are expected, from our experience and from comparison with other high-level results, to lead to very accurate results. Consequently, the spectroscopic data reported in the present work are expected to be very reliable. The accuracy of the potentials is further backed by the generally good agreement between the calculated transport coefficients and experiment. The similar agreement with experiment shown by both the present $a b$ initio potential and the model potential of Ref. 5 lends support to both potentials, and of course to the experimental data used to generate the model potentials. The statistical analyses point to some experimental data being outside the cited error ranges, sometimes significantly so. The very good agreement for $\mathrm{Na}^{+} \cdot \mathrm{Rg}(\mathrm{Rg}$ $=\mathrm{He}-\mathrm{Xe})$ indicates that the calculated transport properties for $\mathrm{Na}^{+}$in $\mathrm{Rn}$ are also accurate. Finally, we note that the $a b$ initio curves are most likely to be the most accurate close to and beyond the potential energy minima for species $\mathrm{Na}^{+}$ - He, which has a very shallow potential energy minimum: such minima are only accessed in low-temperature studies, whereas most scattering and mobility studies occur at room temperature.

\section{ACKNOWLEDGMENTS}

The authors are grateful to the EPSRC for the award of computer time at the Rutherford Appleton Laboratories under the auspices of the Computational Chemistry Working Party (CCWP), which enabled these calculations to be performed, and for a studentship to J.L. E.P.F.L. is grateful to the Research Grant Council (RGC) of the Hong Kong Special Administration Region (HKSAR) and the Research Committee of the Hong Kong Polytechnic University for support. P.S. would like to thank the EPSRC for his present funding at Durham (Senior Research Assistantship). The work of L.A.V. was supported by the National Science Foundation.

${ }^{1}$ P. Soldán, E. P. F. Lee, J. Lozeille, J. N. Murrell, and T. G. Wright, Chem. Phys. Lett. 343, 429 (2001).

${ }^{2}$ J. Lozeille, E. Winata, P. Soldán, E. P. F. Lee, L. A. Viehland, and T. G. Wright, Phys. Chem. Chem. Phys. 4, 3601 (2002).

${ }^{3}$ P. Soldán, E. P. F. Lee, and T. G. Wright, Mol. Phys. 97, 139 (1999).

${ }^{4}$ L. A. Viehland, Chem. Phys. 85, 291 (1984).

${ }^{5}$ A. D. Koutselos, E. A. Mason, and L. A. Viehland, J. Chem. Phys. 93, 7125 (1990)

${ }^{6}$ D. Bellert and W. H. Breckenridge, Chem. Rev. 102, 1595 (2002).

${ }^{7}$ Y. S. Kim and R. G. Gordon, J. Chem. Phys. 60, 4323 (1974).

${ }^{8}$ Y. S. Kim and R. G. Gordon, J. Chem. Phys. 61, 1 (1974).

${ }^{9}$ M. Waldman and R. G. Gordon, J. Chem. Phys. 71, 1325 (1979).

${ }^{10}$ F. A. Gianturco, J. Chem. Phys. 64, 1973 (1976).
${ }^{11}$ T. R. Powers and R. J. Cross, Jr., J. Chem. Phys. 58, 627 (1973).

${ }^{12}$ E. A. Gislason, personal communication.

${ }^{13}$ S. Kita, K. Noda and H. Inouye, J. Chem. Phys. 63, 4930 (1975).

${ }^{14}$ L. A. Viehland and E. A. Mason, J. Chem. Phys. 81, 903 (1984).

${ }^{15}$ C. Nyeland, K. T. Tang, and J. P. Toennies, Chem. Phys. 147, 229 (1990).

${ }^{16}$ A. Freitag, C. van Wüllen, and V. Staemmler, Chem. Phys. 192, 267 (1995).

${ }^{17}$ P. Soldán, E. P. F. Lee, and T. G. Wright, J. Chem. Soc., Faraday Trans. 94, 3307 (1998).

${ }^{18}$ A. Niklass, M. Dolg, H. Stoll, and H. Preuss, J. Chem. Phys. 102, 8942 (1995).

${ }^{19}$ J. J. Wood and A. M. Boring, Phys. Rev. B 18, 27016 (1978).

${ }^{20}$ W. Küchle, M. Dolg, H. Stoll, and H. Preuss, Mol. Phys. 74, 1245 (1991).

${ }^{21}$ E. P. F. Lee and T. G. Wright, J. Phys. Chem. A 103, 7843 (1999).

${ }^{22}$ E. P. F. Lee, S. D. Gamblin, and T. G. Wright, Chem. Phys. Lett. 322, 377 (2000).

${ }^{23}$ S. F. Boys and F. Bernardi, Mol. Phys. 19, 533 (1970).

${ }^{24}$ MOLPRO is a package of $a b$ initio programs written by H.-J. Werner, P. J. Knowles, with contributions from J. Almlöf, R. D. Amos, A. Berning et al. The CCSD treatment is described in: C. Hampel, K. Peterson, and H. J. Werner, Chem. Phys. Lett. 190, 1 (1992).

${ }^{25}$ R. J. LeRoy, LEVEL 7.2-A computer program for solving the radial Schrödinger equation for bound and quasibound levels, and calculating various expectation values and matrix elements. [University of Waterloo Chemical Physics Research Program Report CP-555R (2000)].

${ }^{26}$ L. A. Viehland, Comput. Phys. Commun. 142, 7 (2001).

${ }^{27}$ L. A. Viehland, Chem. Phys. 70, 149 (1982).

${ }^{28}$ L. A. Viehland, Chem. Phys. 179, 71 (1994).

${ }^{29}$ R. Ahlrichs, H. J. Bohm, S. Brode, K. T. Tang, and J. P. Toennies, J. Chem. Phys. 88, 6290 (1988).

${ }^{30}$ G. R. Ahmadi, J. Almlöf, and I. Røeggen, Chem. Phys. 119, 33 (1995).

${ }^{31}$ P. Soldán, E. P. F. Lee, and T. G. Wright, Phys. Chem. Chem. Phys. 3, 4661 (2001).

${ }^{32}$ K. L. Burns, D. Bellert, A. W.-K. Leung, and W. H. Breckenridge, J. Chem. Phys. 114, 2996 (2001).

${ }^{33}$ K. L. Burns, D. Bellert, A. W.-K. Leung, and W. H. Breckenridge, J. Chem. Phys. 114, 7877 (2001).

${ }^{34}$ E. P. F. Lee, P. Soldán, and T. G. Wright, J. Phys. Chem. A 102, 6858 (1998).

${ }^{35}$ E. P. F. Lee, S. D. Gamblin, and T. G. Wright, Chem. Phys. Lett. 322, 377 (2000).

${ }^{36}$ To access this database you must telnet to the computer named sassafrass.chatham.edu and log on as gastrans. The required password will be provided upon request by email to viehland@sassafrass.chatham.edu

${ }^{37}$ G. R. Akridge, H. W. Ellis, R. Y. Pai, and E. W. McDaniel, J. Chem. Phys. 62, 4578 (1975)

${ }^{38}$ M. G. Thackston, M. S. Sanchez, G. W. Neeley, W. M. Pope, F. L. Eisele, I. R. Gatland, and E. W. McDaniel, J. Chem. Phys. 73, 2012 (1980).

${ }^{39}$ L. A. Viehland, Chem. Phys. 78, 279 (1983).

${ }^{40}$ L. A. Viehland, Chem. Phys. 85, 291 (1985).

${ }^{41}$ R. Y. Pai, H. W. Ellis, G. R. Akridge, and E. W. McDaniel, J. Chem. Phys. 63, 2916 (1975).

${ }^{42}$ N. Takata, J. Phys. B 8, 2390 (1975).

${ }^{43}$ R. Moszynski, P. E. S. Wormer, and L. A. Viehland, J. Phys. B 27, 4933 (1994).

${ }^{44}$ P. P. Ong, M. J. Hogan, K. Y. Lam, and L. A. Viehland, Phys. Rev. A 45, 3997 (1992).

${ }^{45}$ K. Bliksaas and H. R. Skullerud, unpublished diploma thesis, Norwegian Institute of Technology (1982).

${ }^{46}$ K. Iinuma, M. Takebe, Y. Satoh, and K. Seto, J. Chem. Phys. 79, 3893 (1983). Data obtained at $310.3<T<315.7 \mathrm{~K}$.

${ }^{47}$ M. J. Hogan and P. P. Ong, J. Phys. D 23, 1050 (1990). Data are adjusted to a gas temperature of $295 \mathrm{~K}$. A slight readjustment of the values occurred after publication, as discussed in M. J. Hogan, Ph.D. thesis, National University of Singapore (1990).

${ }^{48}$ N. Takata, J. Phys. B 10, 2749 (1977). Only data above $40 \mathrm{Td}$ used, as temperature varied for the lower values.

${ }^{49}$ T. H. Lovaas, H. R. Skullerud, O.-H. Kristensen, and D. Lihjell, J. Phys. D 93, 7125 (1990).

${ }^{50}$ T. L. Tan, P. P. Ong, and M. J. Hogan, Phys. Rev. E 48, 1331 (1993).

${ }^{51}$ T. L. Tan, P. P. Ong, and M. J. Hogan, J. Chem. Phys. 100, 586 (1994).

${ }^{52}$ H. W. Ellis, M. G. Thackston, E. W. McDaniel, and E. A. Mason, At. Data Nucl. Data Tables 31, 113 (1984). 